\title{
A RINGED NON-UNIFORM NETWORK: HOW TO RAISE ITS EFFICIENCY
}

\author{
J. Survilo \\ Riga Technical University, \\ 1 Kronvalda Blvd., Riga, LV-1010, LATVIA
}

\begin{abstract}
As distinct from radial electric power lines, in closed loops the consumers are fed from two sides. This is advantageous from the viewpoint of supply reliability, power quality and its losses; however, these are the least only when a loop is uniform, which is not always met in practice. In a non-uniform loop a circulating current flows, and the losses increase proportionally to its square. To reduce losses in such a nonuniform loop, the circulating current should be eliminated. For this purpose a booster transformer can be used. The voltage of such a transformer is known to be in quadrature to the phase voltage; the present consideration has shown that such orientation of the opposing voltage gives the best results only when all loads in the loop are active, otherwise the angle of opposing voltage should be regulated. The voltage value should also be regulated depending on the load. Another technique consists in introducing a complementary reactance into the terminal branches. Such reactance should be regulated if loads are changing in time disproportionately with respect to each other. The best results are achieved when all loop node loads have the same $\cos \varphi$. If the complementary reactance calculated at one end of the loop is positive, then that calculated at the second end of the loop will be negative, and vice versa. The appropriate choice can be made, in particular, involving both loop terminals.
\end{abstract}

Key words: circulating current, non-uniform networks, quadrature booster transformer, power losses.

\section{INTRODUCTION}

For high voltage energy transmission the closed grids are used [1, 2]. If a closed network is non-uniform, excessive electricity losses appear as a result of circulating current in the closed loops of a power line (PL); therefore a problem is to eliminate this circulating current. The medium-voltage grids are built up of radial PLs with single-line service [3]. Such a solution negatively affects the reliability and increases the losses in the line. To improve reliability the open loops are broadly used [4]. When an emergency situation happens somewhere in an open loop, the damaged span is isolated by relay protection, the open loop closes and the energy supply to customers is resumed from the other side. Normally, a loop is broken at the points of current confluence [1], with the objective to simplify the relay protection; this ensures the minimum losses only when in a closed loop (before it had been broken) there was no circulating current; however, when the loads along the loop change this technique does not work. When a medium-voltage grid works as a closed loop (ring-main service [3]), the losses are smaller, provided the circulating current is eliminated, and the reliability at the use of such a technique is yet higher. These and some other advantages are counterweighed by two drawbacks: 1) the necessity to eliminate circulating currents in non-uniform 
grids, 2) the network contains a closed PL loop that is, in fact, a two-terminal line; hence, the relay protection is in this case more complicated. However, owing to the possibilities provided by microprocessor devices, the latter problem can be overcome.

So, in both classes of grid - high-voltage and medium-voltage grids - the operation in a closed loop mode is problematic - it is necessary to eliminate circulating current. This is achieved by introducing a quadrature booster into a closed PL loop, whose voltage sums up with the phase voltage $[5,6]$. This voltage prevents appearance of circulating current. To completely eliminate the circulating current, the magnitude and angle of the voltage provided by a booster transformer are to correspond to the loads of all nodes of the PL loop. The circulating current can be reduced not only by a quadrature booster but also by capacitors introduced into the loop [7, 8]. In the paper, an attempt is made to consider both the alternatives and compare them. To simplify the expressions describing the corresponding processes, the voltage drops and energy losses in the branches of a loop are not taken into account since they have only a minor influence on the loop node loads. If necessary, they can be included into reiterative calculations.

\section{INITIAL CONSIDERATIONS}

At the beginning we shall consider a closed loop with one load (Fig.1a), with the impedances of loop branches being

$\dot{Z}_{1}=R_{1}+j X_{1} ; \quad \dot{Z}_{2}=R_{2}+j X_{2}$.
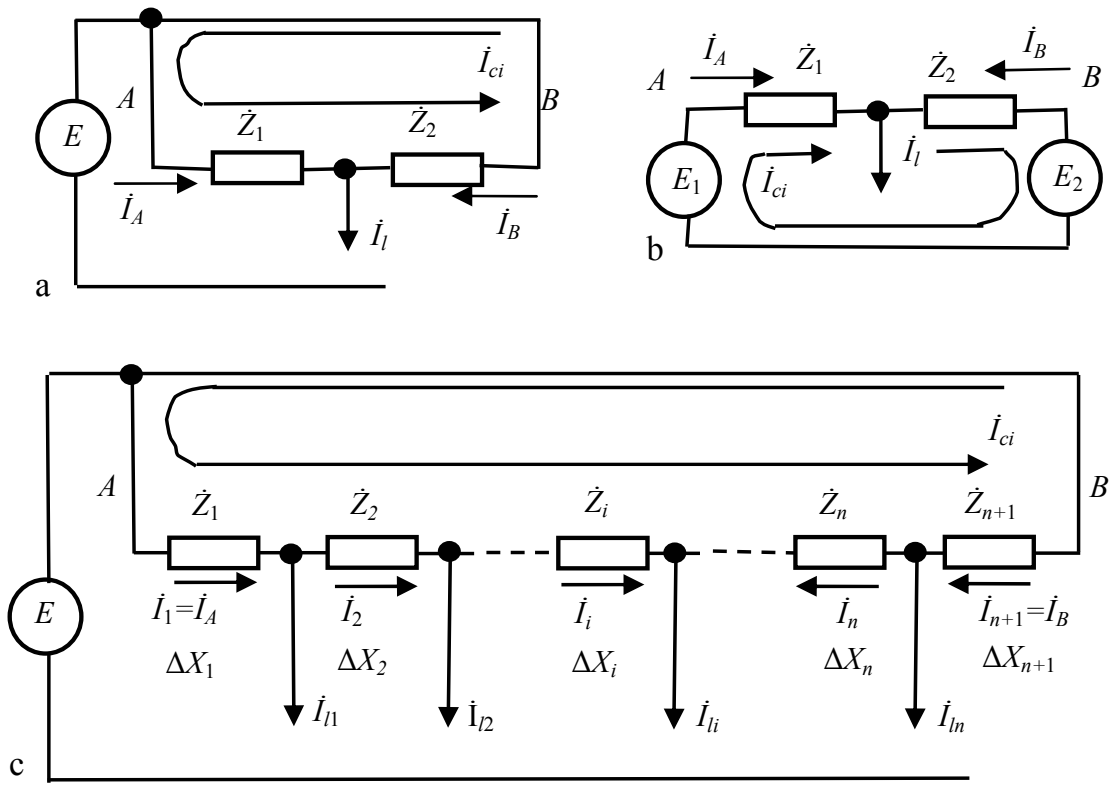

Fig. 1. Loop networks:

$a$ - with one load $\dot{I}_{1} ; b$ - with one load and different voltages $E_{1}$ and $E_{2} ; c$-with a number of loads. $\dot{Z}_{i}$ - impedances of loop branches; $\Delta X_{i}$ - delta reactances; $\dot{I}_{i}$ - currents of branches; $\dot{I}_{c i}-$ circulating current. 
The grid shown in the figure is not met in practice except when there is a double line; but in this case $\dot{Z}_{1}=\dot{Z}_{2}$, which is not of interest for us. The situation when $\dot{Z}_{1} \neq \dot{Z}_{2}$ is the simplest case of a closed loop.

Observing the basic points of the circuit theory we define currents $\dot{I}_{A}$ and $\dot{I}_{B}$ in branches $\dot{Z}_{1}$ and $\dot{Z}_{2}$ (further the branches adjacent to the feeding point are called branch $A$ and branch $B$ ) as

$$
\dot{I}_{A}=\dot{I}_{l} \frac{\dot{Z}_{2}}{\dot{Z}_{1}+\dot{Z}_{2}} ; \quad \dot{I}_{B}=\dot{I}_{l} \frac{\dot{Z}_{1}}{\dot{Z}_{1}+\dot{Z}_{2}} .
$$

If $\dot{Z}_{1}$ and $\dot{Z}_{2}$ are uniform, there is no circulating current, and the power losses are the minimum. To consider the branch currents $\dot{I}_{A}{ }^{\prime}$ and $\dot{I}_{B}{ }^{\prime}$ in non-uniform grids in comparison with the above defined currents $\dot{I}_{A}$ and $\dot{I}_{B}$, the imaginary components of mentioned impedances are changed, and we receive the impedances $\dot{Z}_{1}{ }^{\prime}$ and $\dot{Z}_{2}{ }^{\prime}$ :

$$
\dot{Z}_{1}^{\prime}=R_{1}+j X_{1}^{\prime} ; \quad \dot{Z}_{2}^{\prime}=R_{2}+j X_{2}^{\prime},
$$

hence, at the load current $\dot{I}_{l}$ being the same, we have:

$$
\dot{I}_{A}^{\prime}=\dot{I}_{l} \frac{\dot{Z}_{2}^{\prime}}{\dot{Z}_{1}^{\prime}+\dot{Z}_{2}^{\prime}} ; \quad \dot{I}_{B}{ }^{\prime}=\dot{I}_{l} \frac{\dot{Z}_{1}^{\prime}}{\dot{Z}_{1}^{\prime}+\dot{Z}_{2}^{\prime}} .
$$

Circulating current in branch $A$ will obviously be equal to the difference between the currents in a non-uniform loop and in a uniform loop:

$$
\dot{I}_{c i A}=\dot{I}_{A}{ }^{\prime}-\dot{I}_{A}=\dot{I}_{l}\left(\frac{\dot{Z}_{2}^{\prime}}{\dot{Z}_{1}^{\prime}+\dot{Z}_{2}^{\prime}}-\frac{\dot{Z}_{2}}{\dot{Z}_{1}+\dot{Z}_{2}}\right)=\dot{I}_{l} \frac{\dot{Z}_{1} \dot{Z}_{2}^{\prime}-\dot{Z}_{1}^{\prime} \dot{Z}_{2}}{\left(\dot{Z}_{1}+\dot{Z}_{2}\right)\left(\dot{Z}_{1}^{\prime}+\dot{Z}_{2}^{\prime}\right)} .
$$

Reasoning logically, the circulating current in branch B should change its direction, the module remaining invariable. To verify this, the circulating current in the $B$ direction is determined:

$$
\dot{I}_{c i B}=\dot{I}_{B}{ }^{\prime}-\dot{I}_{B}=\dot{I}_{l}\left(\frac{\dot{Z}_{1}^{\prime}}{\dot{Z}_{1}^{\prime}+\dot{Z}_{2}^{\prime}}-\frac{\dot{Z}_{1}}{\dot{Z}_{1}+\dot{Z}_{2}}\right)=\dot{I}_{l} \frac{\dot{Z}_{1}^{\prime} \dot{Z}_{2}-\dot{Z}_{1} \dot{Z}_{2}^{\prime}}{\left(\dot{Z}_{1}+\dot{Z}_{2}\right)\left(\dot{Z}_{1}^{\prime}+\dot{Z}_{2}^{\prime}\right)} .
$$

From (5) and (6) it logically follows that

$$
\dot{I}_{c i B}=-\dot{I}_{c i A} \text {, }
$$

which means that in the $\dot{Z}_{1}^{\prime}, \dot{Z}_{2}^{\prime}$ loop a circulating current flows.

The equalizing current appears when the voltages at the ends of a twoterminal line (Fig. 1b) are not equal [4]. In a non-uniform loop this current (seen in the A-direction) is:

$$
\dot{I}_{e q}=\frac{\dot{E}_{1}-\dot{E}_{2}}{\dot{Z}_{1}^{\prime}+\dot{Z}_{2}^{\prime}} \text {. }
$$


The summary voltage drop resulting from circulating and equalizing currents is:

$$
\dot{U}_{c i d \Sigma}=\left(\dot{I}_{c i}+\dot{I}_{e q}\right)\left(\dot{Z}_{1}^{\prime}+\dot{Z}_{2}^{\prime}\right)=\dot{I}_{l}\left[\dot{Z}_{2}^{\prime}-\frac{\dot{Z}_{2}}{\dot{Z}_{1}+\dot{Z}_{2}}\left(\dot{Z}_{1}^{\prime}+\dot{Z}_{2}^{\prime}\right)\right]+\left(\dot{U}_{1}-\dot{U}_{2}\right) .
$$

To prevent appearance of circulating current, in such a loop the EMF equal to voltage drop $\dot{U}_{c i d \Sigma}$ and opposed to the circulating current must be applied.

Now we should check whether expression (7) is true for a loop with two loads. For this purpose a loop shown in Fig. $1 c$ is used, assuming $n=3$; we thus have branch impedances $\dot{Z}_{1} ; \dot{Z}_{2} ; \dot{Z}_{3}$ and two node loads $\dot{I}_{l, 1}$ and $\dot{I}_{l, 2}$.

For branch $A$ we have:

$$
\dot{I}_{A}=\frac{\dot{I}_{l, 1}\left(\dot{Z}_{2}+\dot{Z}_{3}\right)+\dot{I}_{l, 2} \dot{Z}_{3}}{\dot{Z}_{1}+\dot{Z}_{2}+\dot{Z}_{3}} ; \quad \dot{I}_{A}{ }^{\prime}=\frac{\dot{I}_{l, 1}\left(\dot{Z}_{2}^{\prime}+\dot{Z}_{3}^{\prime}\right)+\dot{I}_{l, 2} \dot{Z}_{3}^{\prime}}{\dot{Z}_{1}^{\prime}+\dot{Z}_{2}^{\prime}+\dot{Z}_{3}^{\prime}}
$$

with the circulating current

$$
\begin{aligned}
\dot{I}_{c i A}=\dot{I}_{A}{ }^{\prime}-\dot{I}_{A}=\frac{\dot{I}_{l, 1} \dot{Z}_{2}^{\prime}+\dot{I}_{l, 1} \dot{Z}_{3}^{\prime}+\dot{I}_{l, 2} \dot{Z}_{3}^{\prime}}{\dot{Z}_{1}^{\prime}+\dot{Z}_{2}{ }^{\prime}+\dot{Z}_{3}{ }^{\prime}}-\frac{\dot{I}_{l, 1} \dot{Z}_{2}+\dot{I}_{l, 1} \dot{Z}_{3}+\dot{I}_{l, 2} \dot{Z}_{3}}{\dot{Z}_{1}+\dot{Z}_{2}+\dot{Z}_{3}}=\ldots= \\
=\frac{\dot{I}_{l, 1} \dot{Z}_{1}\left(\dot{Z}_{2}^{\prime}+\dot{Z}_{3}^{\prime}\right)+\dot{I}_{l, 2} \dot{Z}_{3}^{\prime}\left(\dot{Z}_{1}+\dot{Z}_{2}\right)-\dot{I}_{l, 1} \dot{Z}_{1}^{\prime}\left(\dot{Z}_{2}+\dot{Z}_{3}\right)-\dot{I}_{l, 2} \dot{Z}_{3}\left(\dot{Z}_{1}^{\prime}+\dot{Z}_{2}^{\prime}\right)}{\left(\dot{Z}_{1}+\dot{Z}_{2}+\dot{Z}_{3}\right)\left(\dot{Z}_{1}^{\prime}+\dot{Z}_{2}{ }^{\prime}+\dot{Z}_{3}^{\prime}\right)} .
\end{aligned}
$$

For branch $B$ these expressions will be:

$$
\begin{aligned}
\dot{I}_{B} & =\frac{\dot{I}_{l, 1} \dot{Z}_{1}+\dot{I}_{l, 2}\left(\dot{Z}_{1}+\dot{Z}_{2}\right)}{\dot{Z}_{1}+\dot{Z}_{2}+\dot{Z}_{3}} ; \quad \dot{I}_{B}{ }^{\prime}=\frac{\dot{I}_{l, 1} \dot{Z}_{1}^{\prime}+\dot{I}_{l, 2}\left(\dot{Z}_{1}^{\prime}+\dot{Z}_{2}{ }^{\prime}\right)}{\dot{Z}_{1}^{\prime}+\dot{Z}_{2}{ }^{\prime}+\dot{Z}_{3}{ }^{\prime}} \\
\dot{I}_{c i B} & =\dot{I}_{B}{ }^{\prime}-\dot{I}_{B}=\frac{\dot{I}_{l, 1} \dot{Z}_{1}^{\prime}+\dot{I}_{l, 2} \dot{Z}_{1}^{\prime}+\dot{I}_{l, 2} \dot{Z}_{2}^{\prime}}{\dot{Z}_{1}^{\prime}+\dot{Z}_{2}^{\prime}+\dot{Z}_{3}^{\prime}}-\frac{\dot{I}_{l, 1} \dot{Z}_{1}+\dot{I}_{l, 2} \dot{Z}_{1}+\dot{I}_{l, 2} \dot{Z}_{2}}{\dot{Z}_{1}+\dot{Z}_{2}+\dot{Z}_{3}}=\ldots= \\
& =\frac{\dot{I}_{l, 1} \dot{Z}_{1}^{\prime}\left(\dot{Z}_{2}+\dot{Z}_{3}\right)+\dot{I}_{l, 2} \dot{Z}_{3}\left(\dot{Z}_{1}^{\prime}+\dot{Z}_{2}^{\prime}\right)-\dot{I}_{l, 1} \dot{Z}_{1}\left(\dot{Z}_{2}{ }^{\prime}+\dot{Z}_{3}{ }^{\prime}\right)-\dot{I}_{l, 2} \dot{Z}_{3}{ }^{\prime}\left(\dot{Z}_{1}+\dot{Z}_{2}\right)}{\left(\dot{Z}_{1}^{\prime}+\dot{Z}_{2}{ }^{\prime}+\dot{Z}_{3}^{\prime}\right)\left(\dot{Z}_{1}+\dot{Z}_{2}+\dot{Z}_{3}\right)} .
\end{aligned}
$$

At two loads, similar to the one-load case, it makes no difference in what terminal branch the circulating current is calculated; its sign in one of them is opposite to that in the other. If regularity (7) is in force for one and two loads, then it also is valid for any number of loads, provided they are connected to a loop isolated from the rest of a network; this also follows from the first Kirchhof's law. Hence, further on, current $\dot{I}_{c i A}$ will stand for circulating current, and the looptracing will be made in the $A$-direction.

\section{THE INSIGHT INTO A CLOSED LOOP OF POWER LINES}

Any loop consists of nodes and branches connecting adjacent nodes. The branch impedance consists of distributed quantities (a power line) or a concentrated 
quantity (a transformer, a current limiting reactor) or both of them, and can be presented as some quantity proportional to its module or to some of its components (real or imaginary) multiplied by corresponding complex factor $\dot{b}$. For example, impedance can be shown as a product of its module $z$ and factor $\dot{b}_{z}$ :

$\dot{Z}=R+j X=z \dot{b}_{z}$,

where

$$
z=\sqrt{R^{2}+X^{2}} ; \quad \dot{b}_{z}=\frac{R}{z}+j \frac{X}{z} .
$$

When the component which characterizes the magnitude of impedance is its active resistance, we can write:

$$
\dot{Z}=R \dot{b}_{R},
$$

where

$\dot{b}_{R}=1+j \frac{X}{R}=1+j \operatorname{tg} \alpha_{z}$.

In uniform grids these complex factors are equal for all branches:

$$
\begin{aligned}
& \dot{b}_{z, 1}=\dot{b}_{z, 2}=\ldots=\dot{b}_{z, n}=b_{u z} ; \\
& \dot{b}_{R, 1}=\dot{b}_{R, 2}=\ldots=\dot{b}_{R, n}=\dot{b}_{u R} .
\end{aligned}
$$

In a non-uniform grid, each of the impedances $\dot{Z}_{1}, \dot{Z}_{2}, \ldots, \dot{Z}_{i}, \ldots \dot{Z}_{n}, \dot{Z}_{n+1}$ (Fig. 1c) of loop branches can be presented as the sum of the uniform impedance and the so-called delta reactance:

$$
\begin{aligned}
\dot{Z}_{i} & =R_{i}+j X_{i}=R_{i}+j X_{u, i}+j \Delta X_{i}= \\
& =\dot{Z}_{u, i}+j \Delta X_{i}=R_{i} \dot{b}_{u R}+j \Delta X_{i} .
\end{aligned}
$$

We can see from (19) that

$$
X_{i}=X_{u, i}+\Delta X_{i}=R_{i} \operatorname{tg} \alpha_{u R}+\Delta X_{i} .
$$

For factor $\dot{b}_{u R}$, hence for $\operatorname{tg} \alpha_{u R}$ of the uniform component of a non-uniform grid, we can take any value convenient for further consideration. Indeed, for any factor $\dot{b}_{u R}$, the real component is 1 , but the imaginary component does not influence impedance $\dot{Z}_{i}$ when the delta reactance $\Delta X_{i}$ is expressed as

$$
\Delta X_{i}=X_{i}-R_{i} \operatorname{tg} \alpha_{R u} .
$$

Now we shall consider the loop with $n$ loads (Fig. 1c). One energy source feeds $\dot{S}_{l, 1} ; \dot{S}_{l, 2} ; \ldots, \dot{S}_{l, n}$ loads from directions $A$ and $B$ through branch impedances $\dot{Z}_{1} ; \dot{Z}_{2} ; \ldots, \dot{Z}_{i} \ldots, \dot{Z}_{n} ; \dot{Z}_{n+1}$. The current through impedance $\dot{Z}_{1}$ (branch $A$ ) is [4]: 


$$
\begin{aligned}
\dot{I}_{A} & =\frac{\dot{I}_{l, 1}\left(\dot{Z}_{2}+\dot{Z}_{3}+\cdots+\dot{Z}_{n+1}\right)+\dot{I}_{l, 2}\left(\dot{Z}_{3}+\cdots+\dot{Z}_{n+1}\right)+\cdots+\dot{I}_{l, n} \dot{Z}_{n+1}}{\dot{Z}_{1}+\dot{Z}_{2}+\cdots+\dot{Z}_{n+1}}= \\
& =\frac{\sum_{k=1}^{n} \dot{I}_{l, k} \sum_{i=k+1}^{n+1} \dot{Z}_{i}}{\sum_{m=1}^{n+1} Z_{m}}
\end{aligned}
$$

If the active resistance of a branch is taken as the basic quantity, for a uniform loop, observing (16) and (18), we obtain:

$$
\dot{I}_{A}=\frac{\sum_{k=1}^{n} \dot{I}_{l, k} \sum_{i=k+1}^{n+1} \dot{Z}_{u, i}}{\sum_{m=1}^{n+1} \dot{Z}_{u, m}}=\frac{\sum_{k=1}^{n} \dot{I}_{l, k} \sum_{i=k+1}^{n+1} R_{i}}{\sum_{m=1}^{n+1} R_{m}} .
$$

In a non-uniform grid we shall have current $\dot{I}_{A}{ }^{\prime}$, which, observing (16), (18) and (19), is:

$$
\dot{I}_{A^{\prime}}=\frac{\sum_{k=1}^{n} \dot{I}_{l, k}\left(\sum_{i=k+1}^{n+1} \dot{Z}_{u, i}+j \sum_{i=k+1}^{n+1} \Delta X_{i}\right)}{\sum_{m=1}^{n+1} \dot{Z}_{u, m}+j \sum_{m=1}^{n+1} \Delta X_{m}} .
$$

For currents $\dot{I}_{B}$ and $\dot{I}_{B}{ }^{\prime}$ formulas (23) and (24) are valid if loads and loop branches are counted in the direction from $B$ to $A$.

The circulating current is the difference between currents $\dot{I}_{A}^{\prime}$, and $\dot{I}_{A}$; observing (19), we have:

$$
\begin{gathered}
\dot{I}_{c i}=\dot{I}_{A}{ }^{\prime}-\dot{I}_{A}=\frac{\sum_{k=1}^{n} \dot{I}_{l, k}\left(\sum_{i=k+1}^{n+1} \dot{Z}_{u, i}+j \sum_{i=k+1}^{n+1} \Delta X_{i}\right)}{\sum_{m=1}^{n+1} \dot{Z}_{u, m}+j \sum_{m=1}^{n+1} \Delta X_{m}}-\frac{\sum_{k=1}^{n} \dot{I}_{l, k} \sum_{i=k+1}^{n+1} \dot{Z}_{u, i}}{\sum_{m=1}^{n+1} \dot{Z}_{u, m}} \\
=j \frac{\sum_{k=1}^{n} \dot{I}_{l, k} \sum_{i=k+1}^{n+1} \Delta X_{i}-\frac{\sum_{m=1}^{n+1} \Delta X_{m}}{\sum_{m=1}^{n+1} R_{m}} \sum_{k=1}^{n} \dot{I}_{l, k} \sum_{i=k+1}^{n+1} R_{i}}{\dot{b}_{u R} \sum_{m=1}^{n+1} R_{m}+j \sum_{m=1}^{n+1} \Delta X_{m}} .
\end{gathered}
$$

From (25) it can be seen that the circulating current depends on all loads in a PL loop. The expression can be simplified if it is assumed that

$$
\sum_{m=1}^{n+1} \Delta X_{m}=0
$$

In accordance with (21), Eq. (26) can be rewritten as 
$\sum_{m=1}^{n+1} \Delta X_{m}=\sum_{m=1}^{n+1} \Delta X_{\Sigma x, m}=\sum_{m=1}^{n+1} X_{m}-\operatorname{tg} \alpha_{\Sigma} x \sum_{m=1}^{n+1} R_{m}=0$

from which we find tangent $\operatorname{tg} \alpha_{\Sigma x}$ of the branch reactance sum:

$\operatorname{tg} \alpha_{\sum x}=\frac{\sum_{m=1}^{n+1} X_{m}}{\sum_{m=1}^{n+1} R_{m}}$.

Now, each branch impedance $\dot{Z}_{i}$ can be presented by (19), where the factor $\dot{b}_{u \Sigma x}$, which, in the similar manner as in (17), can be presented as

$\dot{b}_{u \Sigma x}=1+j \operatorname{tg} \alpha_{\Sigma x}$

can be substituted for $\dot{b}_{u R}$; we therefore will have:

$\dot{Z}_{m}=\dot{Z}_{u \Sigma x, m}+j \Delta X_{\Sigma x, m}$,

where

$\dot{Z}_{u \Sigma x, m}=R_{m} \dot{b}_{u \Sigma x} ; \quad \Delta X_{\Sigma x, m}=X_{m}-R_{m} \operatorname{tg} \alpha_{\Sigma x}$.

Applying preceding formulas to expression (25), we obtain:

$\dot{I}_{c i}=j \frac{\sum_{k=1}^{n} \dot{I}_{l, k} \sum_{i=k+1}^{n+1} \Delta X_{\Sigma x, i}}{\dot{b}_{u \Sigma x} x \sum_{m=1}^{n+1} R_{m}}$.

It can be seen that the circulating current is proportional to the module of the summary delta moment of load currents in the $A$-direction $\left|\sum_{k=1}^{n} \dot{I}_{l, k} \sum_{i=k+1}^{n+1} \Delta X_{\Sigma X, i}\right|$ and is directed relatively to this summary delta moment $\sum_{k=1}^{n} \dot{I}_{l, k} \sum_{i=k+1}^{n+1} \Delta X_{\Sigma x, i}$ with the angle $\pi / 2-\operatorname{arctg} \alpha_{\Sigma x}$.

The voltage drop which appears as a result of circulating current is defined by the expression:

$$
\begin{gathered}
\dot{U}_{c i}=\dot{I}_{c i} \sum_{m=1}^{n+1} \dot{Z}_{m}=\dot{I}_{c i}\left(\sum_{m=1}^{n+1} \dot{Z}_{u, m}+j \sum_{m=1}^{n+1} \Delta X_{m}\right)= \\
=\dot{I}_{c i} \dot{b}_{u \Sigma x} \sum_{m=1}^{n+1} R_{m}=j \sum_{k=1}^{n} \dot{I}_{l, k} \sum_{i=k+1}^{n+1} \Delta X_{\Sigma x, i} .
\end{gathered}
$$

In a uniform loop, the voltage drop is $\dot{U}_{c i}=0$, which complies with expression (33), since in this case all delta reactances according to (19) are zero. 


\section{CIRCULATING CURRENT: WHY SHOULD IT BE ELIMINATED?}

To eliminate circulating currents is rather costly, since it usually requires the use of a booster transformer, current reactors, capacitors for series and shunt compensation - i.e. high-voltage strong-current equipment with regulating and commutating facilities. Communication means are needed to send the load data to the control devices of a PL loop, whereas a microprocessor device is required to process the data and to control the high-voltage equipment. In medium-voltage networks even more sophisticated relay protection should be installed, at the same time a reserve switching device can be removed. However, all this can be outweighed by elimination of energy losses due to circulating current.

The energy losses arise in all branches of the circulating current path. In a uniform loop in Fig. 1c $\Delta X_{1} \ldots \Delta X_{n+1}=0$, the branch impedances are uniform $\dot{Z}_{1}=$ $=\dot{Z}_{u, 1} \ldots \dot{Z}_{n+1}=\dot{Z}_{u, n+1}$ and the branch currents are those which flow in a uniform loop, (i.e. they do not contain circulating current): $\dot{I}_{1}=\dot{I}_{u, 1} \ldots \dot{I}_{n+1}=\dot{I}_{u, n+1}$, respectively. Power losses $P_{l o u}$ in a uniform loop are:

$P_{l o u}=\sum_{m=1}^{n+1} R_{m} \dot{I}_{u, m}^{2}$

In a non-uniform loop the branch currents are:

$\dot{I}_{1}=\dot{I}_{c i}+\dot{I}_{u, 1} \ldots \dot{I}_{n+1}=\dot{I}_{c i}+\dot{I}_{u, n+1}$.

The power loss in the $m$-th branch will be:

$$
\begin{aligned}
& P_{l o, m}=R_{m} \dot{I}_{m} \widehat{I}_{m}=R_{m}\left(\dot{I}_{c i}+\dot{I}_{u, m}\right)\left(\hat{I}_{c i}+\widehat{I}_{u, m}\right)=R_{m} I_{c i}{ }^{2}+R_{i} \dot{I}_{u, m}{ }^{2} \\
& \quad+R_{m}\left(\widehat{I}_{c i} \dot{I}_{u, m}+\dot{I}_{c i} \widehat{I}_{u, m}\right)=P_{l o c i, m}+P_{l o u, m}+P_{l o c i u, m},
\end{aligned}
$$

where $P_{\text {loci, } m}$ is the power loss due to circulating current $\dot{I}_{c i}$;

$P_{l o u, m}$ is the power loss due to current $\dot{I}_{u, m}$ in a uniform loop;

$P_{\text {lociu, } m}$ is the power loss due to interaction of currents $\dot{I}_{c i}$ and $\dot{I}_{u, m}$.

Power loss in the entire non-uniform loop is

$P_{\text {los }}=\sum_{m=1}^{n+1} P_{\text {loci }, m}+\sum_{m=1}^{n+1} P_{\text {lou }, m}+\sum_{m=1}^{n+1} P_{\text {lociu }, m}=P_{\text {loci }}+P_{\text {lou }}+P_{\text {lociu }}$,

where loop losses $P_{l o c i}$ due to circulating current are

$P_{l o c i}=\sum_{m=1}^{n+1} R_{m} I_{c i}{ }^{2}=I_{c i}{ }^{2} \sum_{m=1}^{n+1} R_{m}$.

Losses $P_{\text {lou }}$ are found by Eq. (34), and the losses $P_{\text {lociu }}-$ by the expression:

$P_{\text {lociu }}=\sum_{m=1}^{n+1} R_{m}\left(\widehat{I}_{c i} \dot{I}_{u, m}+\dot{I}_{c i} \widehat{I}_{u, m}\right)=\widehat{I}_{c i} \sum_{m=1}^{n+1} R_{m} \dot{I}_{u, m}+\dot{I}_{c i} \sum_{m+1}^{n+1} R_{m} \widehat{I}_{u, m}$.

In an isolated loop, however, in accordance with the second Kirchhof's law 
$\sum_{m=1}^{n+1} R_{m} \dot{I}_{u, m}=\sum_{m=1}^{n+1} R_{m} \widehat{I}_{u, m}=0$

hence

$P_{\text {lociu }}=0$.

The power losses due to interaction of currents $\dot{I}_{c i}$ and $\dot{I}_{u, m}$ are zero, which means that in a non-uniform loop the power losses are greater than in a uniform one only by the losses $P_{l o c i}$ due to circulating current $\dot{I}_{c i}$. These losses are calculated as the product of the summary active resistance of a loop and the squared circulating power module.

The advisability of measures to be taken to reduce losses depends on the savings that could be obtained due to elimination of losses $P_{\text {loci }}$.

\section{MEASURES TO RAISE THE EFFICIENCY \\ OF CLOSED NON-UNIFORM LOOPS}

According to expression (33) the voltage drop in a PL loop as a result of circulating current is equal to the summary delta moment of load currents in the $A$ -

direction $\sum_{k=1}^{n} \dot{I}_{l, k} \sum_{i=k+1}^{n+1} \Delta X_{\Sigma x, i}$, being in phase quadrature to it. To upgrade a loop, the circulating current is to be eliminated, and for this reason the opposing voltage is applied (in the opposite direction to the voltage drop, hence also in quadrature to the mentioned delta moment of load currents). Its direction relatively to the circulating current can be determined using Eqs. (32) and (33):

$\frac{\dot{U}_{c i}}{\dot{I}_{c i}}=\dot{b}_{u \Sigma x} \sum_{m=1}^{n+1} R_{m}$

The angle between these values, observing (28), is found from the expression:

$\arg \left(\frac{\dot{U}_{c i}}{\dot{I}_{c i}}\right)=\arg \left(\dot{b}_{u \Sigma x}\right)=\operatorname{arctg} \frac{\sum_{m=1}^{n+1} X_{m}}{\sum_{m=1}^{n+1} R_{m}}$.

However, this angle is poorly informative, so we shall proceed further. If the place for installation of a booster transformer is at points $A$ or $B$, through it current $\dot{I}_{A}$ or $\dot{I}_{B}$ flows instead of $\dot{I}_{A}{ }^{\prime}$ or $\dot{I}_{B}{ }^{\prime}$. By virtue of (33) and (23) we obtain:

$\frac{\dot{U}_{c i}}{\dot{I}_{A}}=j \sum_{m=1}^{n+1} R_{i} \frac{\sum_{k=1}^{n} \dot{I}_{l, k} \sum_{i=k+1}^{n+1} \Delta_{\Sigma x, i}}{\sum_{k=1}^{n+1} \dot{I}_{l, k} \sum_{i=k+1}^{n+1} R_{i}}$.

From (44) it follows that the angle between the $A$-direction current in a uniform (or upgraded) loop and the opposing voltage is: 
$\beta=\arg \frac{\dot{U}_{c i}}{\dot{I}_{A}}=\pi / 2+\arg \left(\frac{\sum_{k=1}^{n} \dot{I}_{l, k} \sum_{i=k+1}^{n+1} \Delta X_{\Sigma x, i}}{\sum_{k=1}^{n} \dot{I}_{l, k} \sum_{i=k+1}^{n+1} R_{i}}\right)$.

It is assumed that the phase $A$ voltage is a real quantity. Then angle $\varphi$ between current $\dot{I}_{A}$ and the phase voltage is

$\varphi=\arg \left(\dot{I}_{A}\right)$.

Angle $\delta$ between voltage drop $\dot{U}_{c i}$ and phase voltage $\dot{U}_{f}$ is the sum:

$\delta=\beta+\varphi$.

It is obvious that the opposing voltage is not in quadrature to the phase voltage (as is sometimes asserted in literature, see, e.g. $[5 ; 9 ; 10]$ ), which is proved by the examples using previous formulas. The opposing voltage is in quadrature to the phase voltage exclusively when all loads are fully shunt-compensated (in this case there is no reactive current in the branches). This can reduce the effectiveness of measures against circulating current using a quadrature booster in the cases of poorly compensated reactive loads.

As concerns the opposing voltage magnitude, it depends on a PL loop's parameters, which manifest themselves in $\Delta X_{\Sigma x, i}$ and in the complex values of load currents $\dot{I}_{l, k}, k=1 \ldots n$. This means that the communication tools should be ready to transmit these load quantities to a control device, which would process the incoming data and issue the necessary command to a booster transformer to match the magnitude of opposing voltage and its direction.

The place for installation of a booster transformer in the loop should be chosen in such a way that the rated total power is the minimum. This means that the booster transformer is to be installed at one of the two points, $A$ or $B$, at which the module of current is smaller.

The opposing voltage is oriented towards a feeding terminal current $\left(\dot{I}_{A}\right.$ or $\dot{I}_{B}$ ) at $90^{\circ}$ only when all loads are fully compensated or compensated to the same degree. If this voltage is not in quadrature to the terminal current, the booster transformer has to transmit both reactive and active power. If installed at some point inside a loop, its power can be lower but the opposing voltage will be still more dependent on the loads in the loop.

The measure based on the use of a quadrature booster has, however, a shortcoming: for its successfulness two quantities should be regulated - the magnitude and the angle of opposing voltage. The booster transformer method is rather expensive even when it has only the magnitude regulation, to leave alone the angle regulation.

As an alternative option, we will consider the one involving circulating voltage, with the use of Eq. (25) for the circulating current and Eq. (19) for branch impedance $\dot{Z}_{i}$, i.e.: 
$\dot{U}_{c i}=\dot{I}_{c i} \sum_{m=1}^{n+1} \dot{Z}_{m}=j\left[\sum_{k=1}^{n} \dot{I}_{l, k} \sum_{i=k+1}^{n+1} \Delta X_{i}-\frac{\sum_{m=1}^{n+1} \Delta X_{m}}{\sum_{m=1}^{n+1} R_{m}} \sum_{k=1}^{n} \dot{I}_{l, k} \sum_{i=k+1}^{n+1} R_{i}\right]$.

We will try to make useless circulating voltage by changing the parameters of a PL loop. So, when

$\dot{U}_{c i}=0$,

we have

$$
\frac{\sum_{m=1}^{n+1} \Delta X_{m}}{\sum_{m=1}^{n+1} R_{m}}=\frac{\sum_{k=1}^{n} \dot{I}_{l, k} \sum_{i=k+1}^{n+1} \Delta X_{i}}{\sum_{k=1}^{n} \dot{I}_{l, k} \sum_{i=k+1}^{n+1} R_{i}} .
$$

The right-hand side of Eq. (50) depends on the load currents and on the parameters of $2 \ldots n+1$ branches and will remain unchanged. It is convenient to present this side as

$$
\frac{\sum_{k=1}^{n} \dot{I}_{l, k} \sum_{i=k+1}^{n+1} \Delta X_{i}}{\sum_{k=1}^{n} \dot{I}_{l, k} \sum_{i=k+1}^{n+1} R_{i}}=\operatorname{tg} \alpha_{\Sigma \Delta} .
$$

With the existing line loop parameters equity (50) is not fulfilled, so it would be worthwhile to change the numerator or the denominator. The active resistance cannot be reduced; at the same time, it would obviously be contra-productive to raise it. Therefore we will change the numerator by adding to it some complementary reactance $X_{c}$.

Now, observing (51), we have

$$
X_{c}+\sum_{m=1}^{n+1} \Delta X_{m}=\operatorname{tg} \alpha_{\Sigma \Delta} \sum_{m=1}^{n+1} R_{m},
$$

which, observing (26), gives the sought-for complementary reactance as

$$
X_{c}=\operatorname{tg} \alpha_{\Sigma \Delta} \sum_{m=1}^{n+1} R_{m} .
$$

The complementary reactances calculated for branch $A$ and $B$ have opposite signs. It is so since currents $\dot{I}_{A}$ and $\dot{I}_{B}$ are directed oppositely, while the opposing voltage is oriented in the same directions in branches $A$ and $B$. If $X_{c}$ calculated at terminal $A$ is positive, it can be realized connecting the inductance in series with branch $A$. The same result can be achieved if we calculate the complementary reactance at terminal $B$ and connect it in series with branch $B$. This reactance, being negative, can however be provided by capacitors. If at terminal $A$ the complementary reactance is negative, then at terminal $B$ it will be positive. In practice, a 
more advantageous choice of complementary reactance (a current reactor or capacitor) can be made. The option of involving both loop terminals, at one of them being inductance and at the other - capacitance, can be considered as well.

When analyzing Eq. (51) it turns out that $\operatorname{tg} \alpha_{\Sigma \Delta}$ is real only when all load currents are shunt-compensated to the same degree, since complementary reactance $X_{c}$ also is real by this condition. In this case, the complementary reactance is more advantageous as compared with a booster transformer, since the latter requires regulating the magnitude and angle of the opposing voltage by the mentioned condition. The complementary reactance should be regulated if all loads change in time disproportionately with respect to each other.

\section{CONCLUSIONS}

1. In a non-uniform PL loop the power losses increase by the product of the loop's active resistance and the squared circulating current.

2. The voltage of a booster transformer should be in quadrature to the phase voltage exclusively when all loads are fully shunt-compensated. There exists dependence between the magnitude of a booster transformer's voltage and its orientation against the phase voltage on the one hand, and the loop branch impedances and loop node load data on the other.

3. The booster transformer's voltage is oriented towards the feeding terminal current $\left(\dot{I}_{A}\right.$ or $\left.\dot{I}_{B}\right)$ at $90^{\circ}$ only when all loads are fully compensated or compensated to the same degree. If this condition is not fulfilled, a booster transformer transmits reactive and active power.

4. Complementary reactances connected in series with branch $A$ or/and $B$ are calculated based on the parameters of PL loop branches.

5. Complementary reactances calculated for branches $A$ and $B$ have opposite signs. A positive reactance is realized using inductance (e.g. a current reactor) and a negative - using capacitance (capacitors). In practice, it is necessary to make appropriate choice as to what reactance (positive or negative or both) and, correspondingly, in what branch should be applied.

6. For the best results, complementary reactance can be regulated in the case when loads change in time disproportionately.

\section{REFERENCES}

1. Vanags, A. (2007). Elektriskie tīkli un sistèmas, I daļa. Rīga: RTU (6. nod.).

2. ENK5 - CT 2001 - 00522. DISPOWER. Distributed generation with high penetration of renewable energy sources. Structure and data concerning electrical grids for Italy, Germany, Spain, UK, Poland. www.iset. Uni-kassel.de/dispower.

3. EIG-B-connection-MV-network.pdf. Chapter B, Connection to the MV utility distribution network. www. electrical-installation.schneider-electric.com.

4. Блок, В.М. (1986). Электрические сети и системы. Москва: Высшая школа (гл. 4).

5. Miller, H., \& Malinowski, H. (1993). Power System Operation. San Francisko (California): Mc Graw Hill (Ch. 2).

6. Vanags, A., \& Krišāns, Z. (2005). Elektriskie tīkli un sistēmas, II daļa. Rīga: RTU (4. nod.).

7. Идельчик, В.И. (1989). Электрические системы и сети. Москва: Энергоатомиздат (гл. 3). 
8. Холмский В.Г. (1975). Расчет и оптимизаџия режимов электрических сетей (специальные вопросы). Москва: Высшая школа (гл. 6).

9. Quadrature booster, www.en.wikipedia.org/wki.

10. The specification and application of large quadrature boosters to restrict post-fault power flows. www.egelec.com/arabic/related sites.

\section{SLĒGTIE GREDZENVEIDĪGIE TĪKLI, TO EFEKTIVITĀTES PAAUGSTINĀŠANA}

\section{J. Survilo}

Kopsavilkums

Atškirīibā no radiālajām elektriskajām līnijām slēgtajā gredzenveidīgā tīklā patērētāji tiek baroti no divām pusēm. Priekšrocība ir tā, ka ir lielāka elektroenerǵijas piegādes drošība un labāka elektroenerğijas kvalitāte, kā arī mazāki elektroenerğijas zudumi. Bet zudumi ir mazāki tikai tad, ja tīkls ir homogēns, kas ne vienmēr īstenojas praksē. Nehomogēnajos tīklos ir cirkulējošā strāva, un zudumi palielinās par lielumu, proporcionālu cirkulējošās strāvas kvadrātam. Lai samazinātu zudumus nehomogēnajā gredzenā, ir jānovērš cirkulējošā strāva. Šim nolūkam lieto būstertransformatoru. Ir pieņemts, ka būstertransformatora spriegums ir vērsts taisnā lenkkī pret fāzes spriegumu. Šie pētījumi parādīja, ka šādi var iegūt vislabākos rezultātus tikai tad, kad visas līniju gredzena slodzes ir aktīvas, citādi leņkis ir jāregulē. Arī sprieguma vērtība jāregulē atkarībā no slodzēm. Cirkulējošo strāvu var arī novērst, ieslēdzot sākuma zaros papildus reaktīvo pretestību. Šì pretestība ir jāregulē, ja slodzes mainās laikā neproporcionāli savā starpā. Vislabākais rezultāts ir sasniegts, kad visām gredzena mezglu slodzēm ir vienāds $\cos \varphi$. Ja papildus pretestība, rēķināta pie viena gredzena gala, ir pozitīva, tad papildus pretestība, rēķināta otrā gredzena galā, būs negatîva un otrādi. Jāizvēlas labākais variants, tai skaitā izmantojot abus gredzena galus.

10.11.2008. 